\title{
Percutaneous Coronary Intervention (PCI) in Patients with Chronic Total Occlusion (CTO): A Single Center Experiences
}

\author{
AHMW Islam, S Munwar, S Talukder, AQM Reza \\ Dept. of Interventional and Invasive Cardiology, Apollo Hospitals, Dhaka
}

Keywords:

Chronic total

occlusion,

PCI,

Drug Eluting

Stent,

Bare Metal

Stent

\begin{abstract}
:
Background: Aim of the study was to evaluate the primary in-hospital success and

30-days survival outcome of PCI in patients with CTO lesions, using either Bare-metal stents (BMS) or Drug Eluting Stent (DES) like Sirolimus-eluting or Paclitaxel-eluting stent in our hospital setting.

Methods: Total 50 patients were randomized as per the definition of CTO, from a total of 400 patients who had PCI at our center in the quantifying period. After the guidewire crossing and the balloon dilation, measurement of the culprit lesion was done by using Siemens QCA measuring system. Among the patients, Male: 41 and Female: 9. Mean age were for Male: 53.3yrs, for Female: 64.4 yrs. Associated CAD risk factors were Dyslipidemia, High Blood pressure, Diabetes Mellitus, Positive FH for CAD and Smoking.

Results: Our study results show 50 patients (12.5\%) had CTO lesion out of total 400 PCI procedures. Sex distribution in male 41 (82\%), Female 9 (18\%). Among the study group; 38 (76\%) were Dyslipidemic, 31 (62\%) were hypertensive; 20 (40\%) patients were Diabetic, 9 (22\%) were all male smoker, 5 (10\%) were having positive FH for CAD. Female patients were more obese and developed $C A D$ in advance age (male: 53.5 Versus Female: 64.4 yrs). Average diameter of stented vessel was greater in RCA than LAD and LCX. We found that the incidences of CTO lesions were more in $L A D$ territory 20 (40\%) followed by RCA 17 (34\%) and LCX 13(26\%). Single vessel Disease (SVD) in 45 (90\%) patients was more common type of CTO lesion followed by Double vessel disease (DVD) in $5(10 \%)$. Post procedural, in-hospital and 30 days survival out comer was $100 \%$ in our present study.

Conclusion: Our study has revealed that PCI in patients with CTO lesions has increased inhospital and 30 days survival outcome, are treated with BMS or DES. The incidence of CTO lesion is more common in male than in female. Female are developing heart disease in advance age and are more obese.
\end{abstract}

(Cardiovasc. j. 2010; 2(2) : 168-174)

\section{Introduction:}

With the advances of management, patients with Acute Myocardial Infarction (AMI) or Acute Coronary Syndrome (ACS), by Percutaneous coronary Intervention (PCI) by using bare metal stent (BMS) reduces the acute closure or late restenosis compared with balloon angioplasty alone, has already established. ${ }^{1-2}$ With the property of site specific antiproliferating drug delivery system by drug eluting stent (DES) reduces the clinical and angiographic restenosis by $<10 \%$ by inhibiting neointimal hyperplasia. ${ }^{3-4}$ Several studies have shown increase in procedural success and survival out come with the reduction of MACE and late luminal loss and restenosis by Sirolimus eluting stent than bare metal stent. ${ }^{5-6}$ Vessel size, specially small vessel with increase in tortuosity, diabetes with complex lesion, lengthy plaque are major contributory factors in stent restenosis. In the Drug stent era, successful PCI in CTO lesions is really a great challenge for interventionist. In this present study, we have evaluated primary end point of 30 days survival out come after successful PCI in patients with CTO lesion.

\section{Primary End points:}

Primary end-points were considered to be acute or sub-acute stent thrombosis, death, Q-wave myocardial infarction, urgent $\mathrm{CABG}$ or repeat PCI within the 30days of the original procedures.

Address of Correspondence : Dr. A H M Waliul Islam, Dept of Interventional and Invasive cardiology, Apollo Hospitals Dhaka, Bangladesh. E-mail: ahmwislam@apollodhaka.com 


\section{Methods:}

Definition:

Chronic Total occlusion(CTO) lesion was defined as an angiographically, no antegrade filling of distal vessel other than via collaterals. All patients included had a native vessel occlusion estimated to be of at least one month's duration ${ }^{7}$ based on either a history of sudden chest pain or a previous myocardial infarction in the same target territory, the evidence of ischaemia related to target vessel (signs of ischaemia during an abnormal TMT (ST depression $>1.0 \mathrm{~mm}$ horizontal or down sloping or up sloping ST depression $>2.0 \mathrm{~mm}$ or signs of ongoing angina with the ECG changes on the target territory). However, temporal criteria to define CTO lesion was ranging from $>2$ weeks to $>3$ months. In general lesions with $>3$ months were considered as Chronic according to the AHA/ACC lesion classification. The estimated length of the occlusion was measured from the point of the total occlusion to the most proximal part of the distal vessel which was visualized by collaterals filled by contrast. ${ }^{5,} 8$ Consents were taken from all these patients.

\section{Patient Population:}

Patients were randomized from the all PCI procedures at our centers as per definition of CTO lesions were included in this study. Study period was from January 2007 to June 2009.

Total 56 CTO was attempted and 6 patients were excluded from the study due to guide wire crossing failure. Total 5 patients had DVD, for which PCI was done in addition to the targeted CTO lesion.

PCI either were done with BMS or DES. DES included Cypher (Cordis, USA) and TAXUS (Boston Scientific, USA). The BMS included MultilinkVision, Zeta (Guidant, USA) and micro-Driver (Medtronic, USA) and Genous (Orbus, Netherlands). Coronary angioplasty was performed according to standard rules. Neither ablative techniques (rotablator, directional atherectomy) nor cutting balloon were used. Predilatation was optional before stent implantation with a shorter balloon to avoid geographic miss. A successful procedures was defined as TIMI-3 antegrade flow, and $<20 \%$ residual stenosis in two orthogonal views.
Post-deployment dilation was performed at high inflation pressure in all patients.

Drug Therapy:

All the patients received Aspirin $300 \mathrm{mg} /$ day and Clopidegrol as a loading dose $300 \mathrm{mg}$ prior to PCI and recommended to continue for at least 9 months and received atorvastatin along with standard Medical management for CAD. During the procedure, an intravenous heparin bolus (100IU/ $\mathrm{Kg}$ ) and GP IIb/IIIa receptor blocker Integrilin were administered as required. The use of GP IIb/IIIa Receptor blocker was recommended as per protocol. Quantitative angiographic measurements of the target lesion were obtained in order to deploy correct size stent. In the event of chest pain, postprocedural ECG and CPK were measured and compared with the baseline. Check angio were taken, whenever indicated.

\section{Statistical analysis:}

All data were expressed as mean \pm SD (Quantitative variables) and percentile of distribution (categorical). Body mass Index (BMI) were calculated as body weight in $\mathrm{kg}$ divided by height in sq meter $\left(\mathrm{kg} / \mathrm{m}^{2}\right)$.

\section{Results:}

PCI were performed in total 50 patients (Male 41, Female 9) with CTO lesion. Female are older than male (male $53.3 \pm 9.9$ vs female: $64.4 \pm 11.9$ ) and more obese (BMI in male: $25.5 \pm 2.8$ vs female $26.4 \pm 3.2)$. Both systolic and Diastolic BP were higher in female than male (Male: Female $136 \pm$ 18.2 vs148.2 \pm 33.2 : $79.8 \pm 11.9$ vs $85 \pm 11.2$ ). Average number of CAD risk factors were higher in male than female $(2.3 \pm 1.1: 2.1 \pm 0.8)$.

Table-I

Demographic Profile of Patients

\begin{tabular}{lcc}
\hline & Male & Female \\
\hline Number & 41 & 9 \\
Age $(\mathrm{yrs})$ & $53.25 \pm 9.9$ & $64.4 \pm 11.9$ \\
$\mathrm{BMI}\left(\mathrm{kg} / \mathrm{m}^{2}\right)$ & $25.5 \pm 2.8$ & $26.4 \pm 3.2$ \\
$\mathrm{SBP}(\mathrm{mmHg})$ & $136.0 \pm 18.2$ & $148.2 \pm 33.2$ \\
$\mathrm{DBP}(\mathrm{mmHg})$ & $79.8 \pm 11.9$ & $85.0 \pm 11.2$ \\
No.of Risk Factor & $2.3 \pm 1.1$ & $2.1 \pm 0.8$ \\
\hline
\end{tabular}

Data were presented as Mean $\pm \mathrm{SD}$ 
Table-II

Average size of Stent used with inflation pressure

\begin{tabular}{lccc}
\hline & Length $(\mathrm{mm})$ & Diameter $(\mathrm{mm})$ & Inflation Pressure(ATM) \\
\hline LAD & $24.2 \pm 6.1$ & $2.9 \pm 0.4$ & $13.9 \pm 1.9$ \\
LCX & $18.3 \pm 5.3$ & $2.8 \pm 0.5$ & $13.1 \pm 1.6$ \\
RCA & $23.9 \pm 5.9$ & $3.3 \pm 0.3$ & $14.9 \pm 2.9$ \\
\hline
\end{tabular}

Data were presented as Mean \pm SD

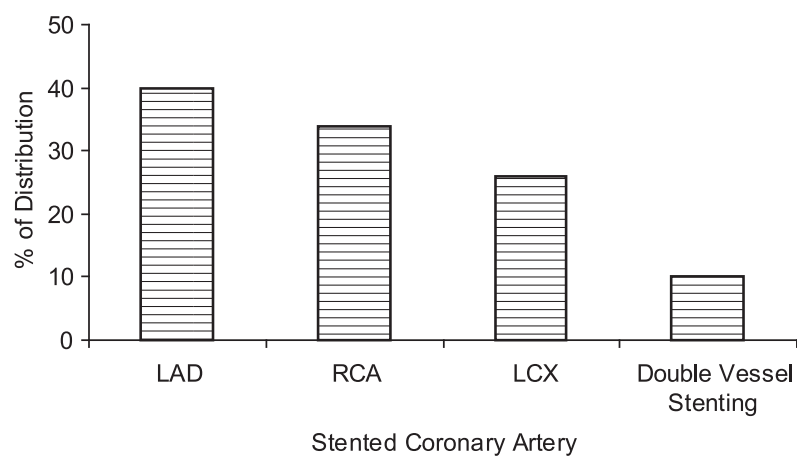

Fig.-1: Showing the percentage wise distribution of PCI in CTO lesions as to, LAD in 20 patients (40\%), PCI to RCA in 17 patient (34\%) and PCI to LCX in 13 patients (26\%)were done.

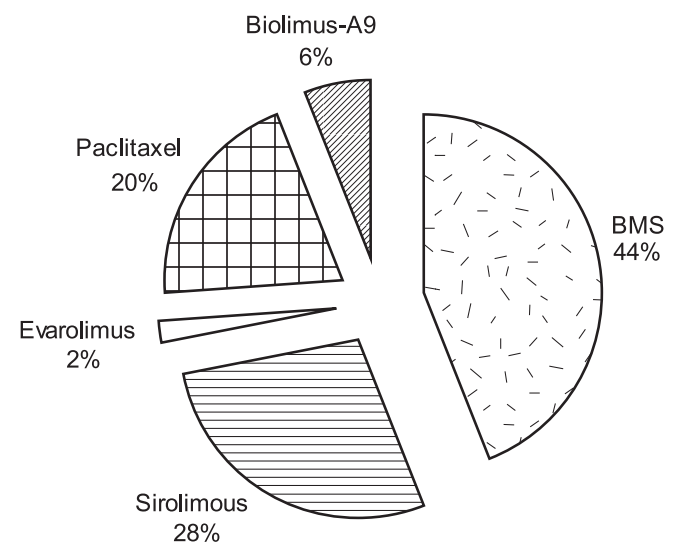

Fig.-2: Pie graph Showing percentage distribution of the type of stent used, BMS 22 (44\%) followed by Sirolimus-eluting stent 14 (28\%) and Paclitaxel-eluting stent 10 (20\%), Zotarolimus-eluting stent 3 (6\%), Everolimuseluting stent $1(2 \%)$.

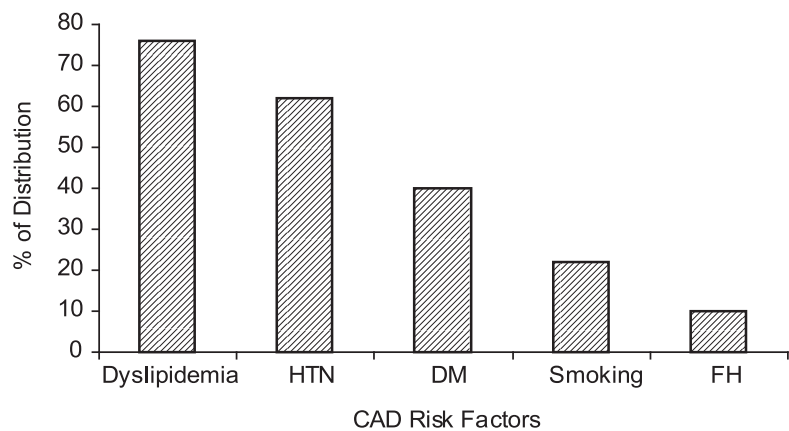

Fig.-3: Distribution of risk factors among the study population.

Among the Coronary artery disease (CAD) risks factors, Fig 3. showing that Dyslipidemia is the predominant risk factors in $38(76 \%)$ patients followed by HTN in 31 (62\%), DM in 20 (40\%), positive $\mathrm{FH}$ in $5(10 \%)$ and smoker in $9(22 \%)$ patients (all male). ECG evidenced diagnosis on arrival at ER was: Anterior MI 14(28\%), Inferior MI 12(24\%), Infero-post MI 4 (8 \%) and NSTEMI 5(10\%) and Unstable Angina 15 (30\%).

Fig 4 shows the PCI in a female patient with CTO lesion in proximal LAD, arrowed indicated a) Total occlusion at proximal LAD, b) Guide wire crossing the occluded CTO lesion c) \& d) Ballooning in occluded segment e) stenting in occluded CTO lesion and f) post PCI with re-establishment of TIMI III distal flow. Fig 5 shows the PCI in a male patient with CTO lesion in proximal LAD, arrow indicated clockwise a) Total occlusion at proximal LAD, b) $1^{\text {st }}$ ballooning at the occluded segment c) mild opening with distal flow, d) further ballooning, e) Stenting in the occluded segment; f) post PCI with re-establishment of TIMI III distal flow . 


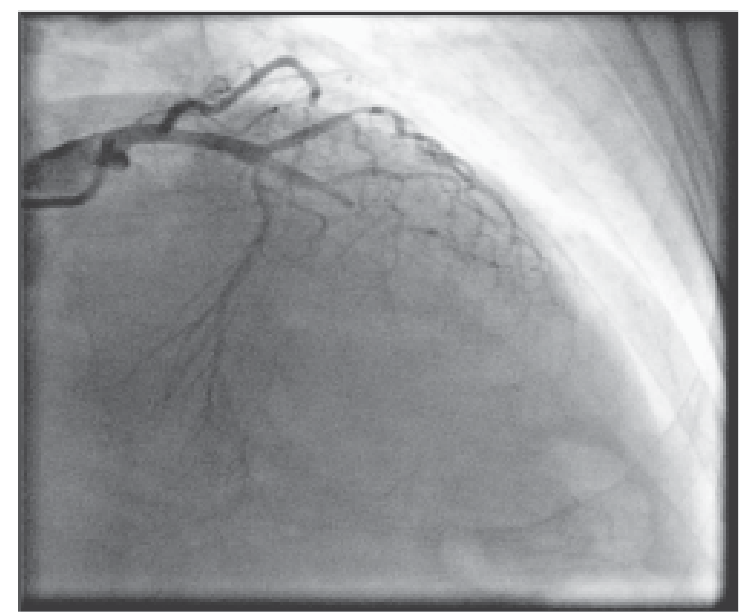

a

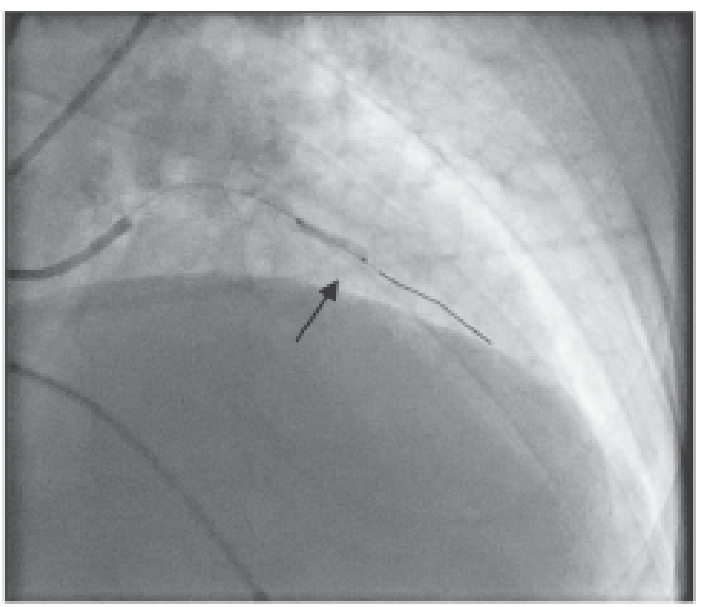

$\mathrm{C}$

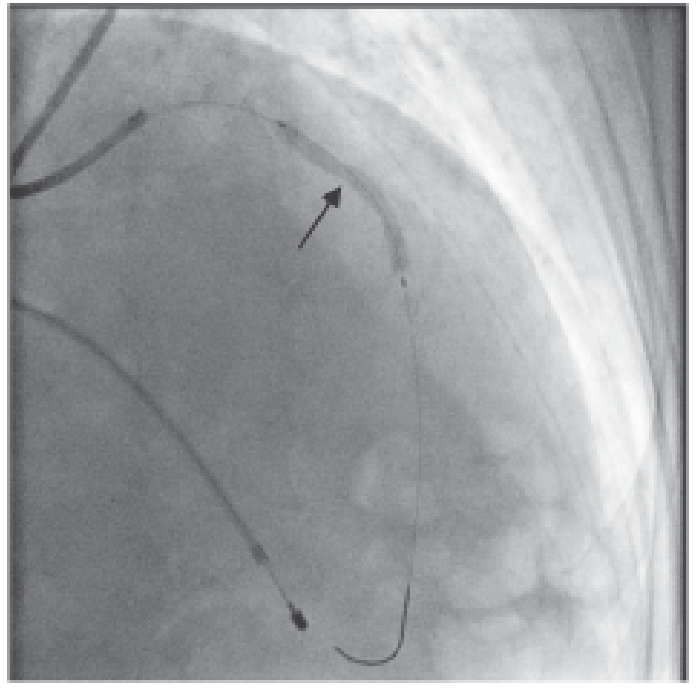

e

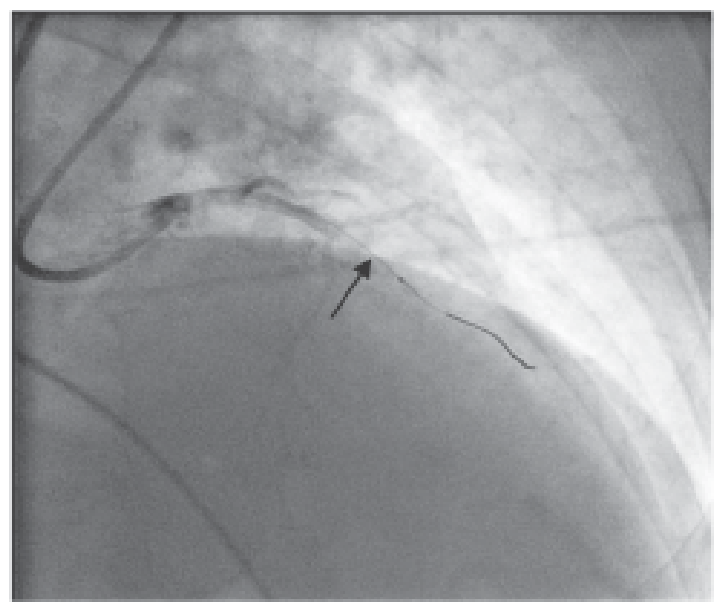

b

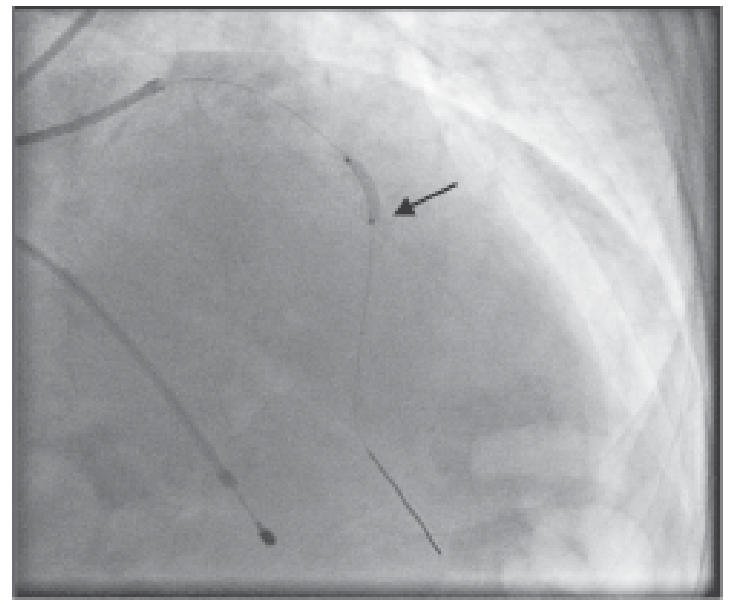

d

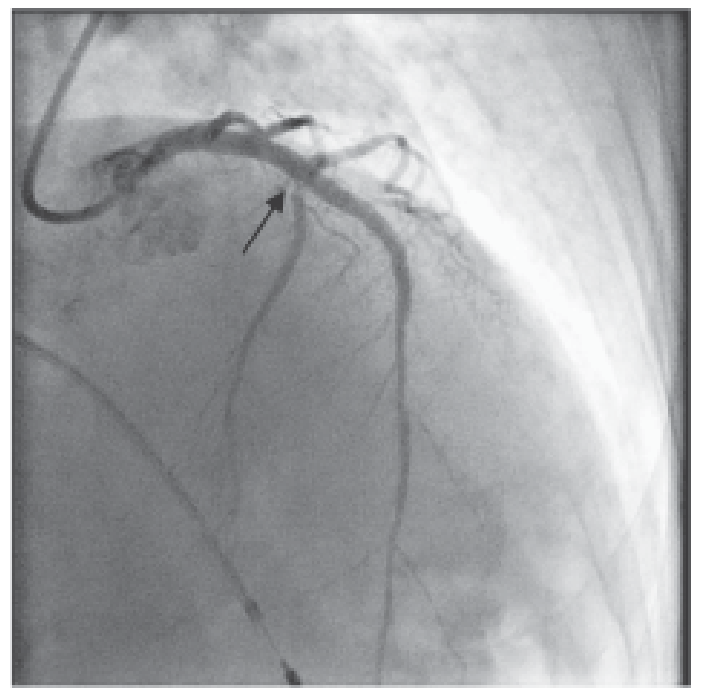

f

Fig.-4: Showing the Coronary Angiography of a CTO lesion and subsequent opening and re-establishment of TIMI III distal flow in a patient CTO lesion in Proximal LAD of a female patient; a) Occluded Lesion in Proximal LAD, b) Balloon supported guidewire crossing, c) \& d) Ballooning; e)Stenting in occluded segment; f) Post PCI Establishment of flow. 


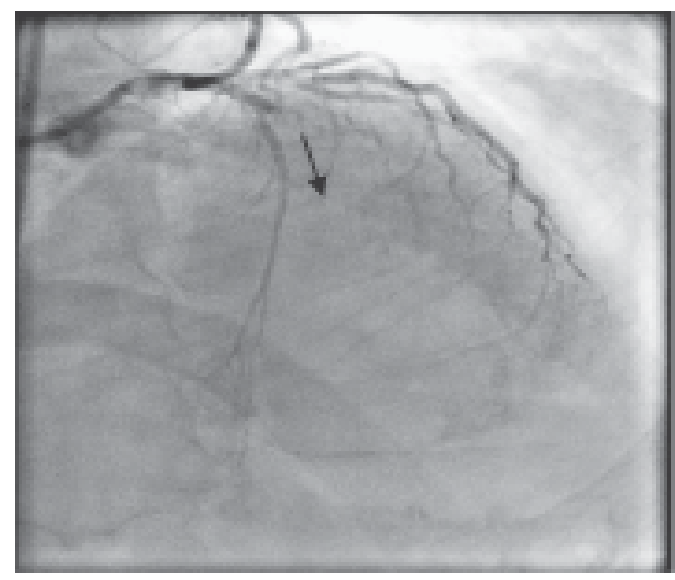

a

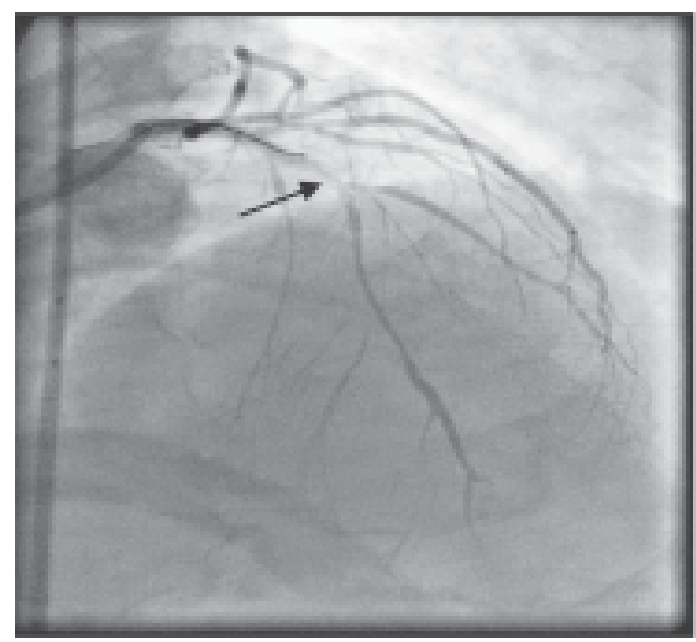

c

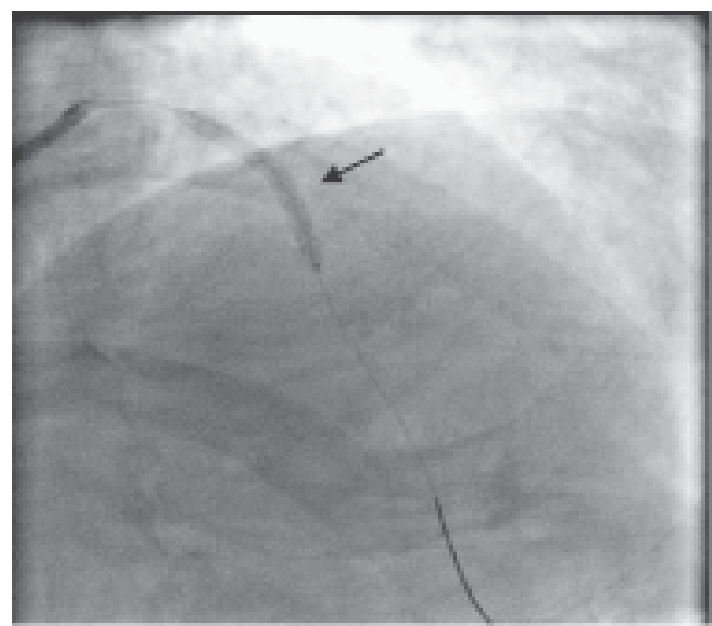

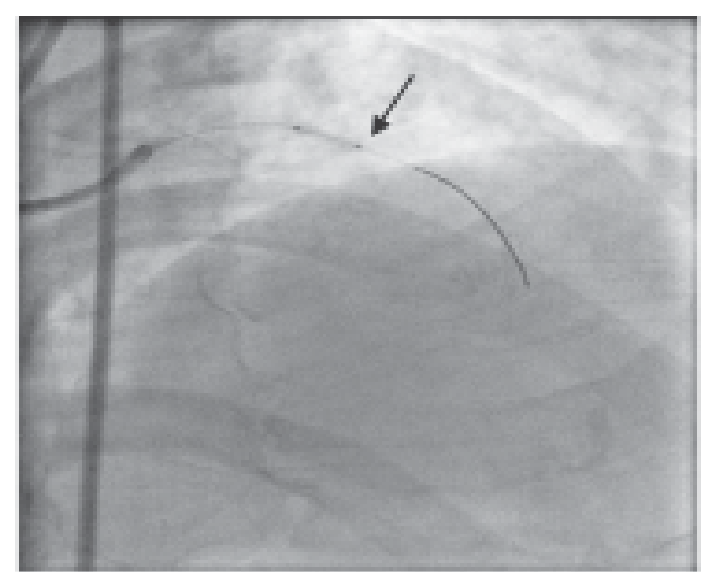

b

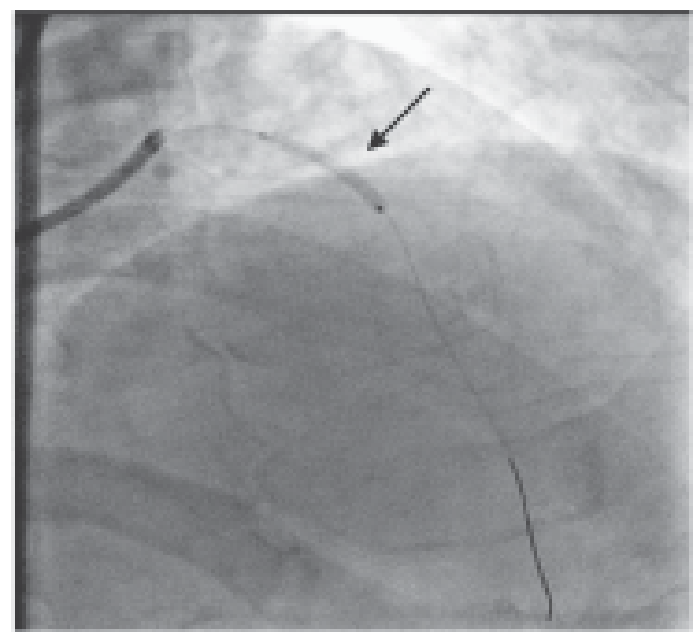

d

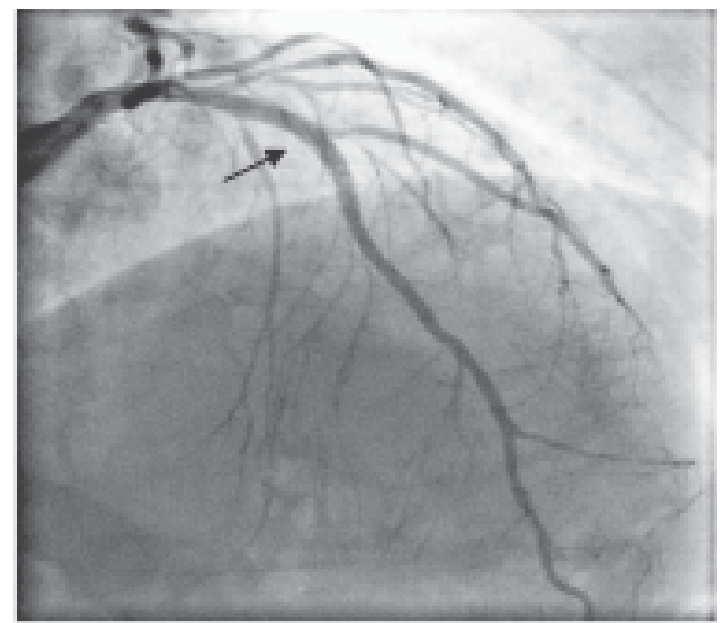

$f$

Fig.-5: Showing the Coronary Angiography of a CTO lesion and subsequent opening and re-establishment of TIMI III distal flow in a patient CTO lesion in Proximal LAD of a male patient; a) Occluded lesion in Proximal LAD, b) $1^{\text {st }}$ Ballooning after guidewire crossed; c) Mild opening with distal flow; d) Further Ballooning; e)Stenting in occluded segment; f) Post PCI Establishment of flow. 


\section{Discussion:}

By definition, a CTO lesion, is a lesion of more than 3 months duration with thrombolysis in myocardial infarction (TIMI) grade 0 or I- distal flow. ${ }^{9}$ In the absence of serial angiogram, clinical timing of Acute MI or angina with ECG changes consistent with the location of occlusion is helpful to estimate the duration of occlusion.

Intervention in CTO lesion is a major challenge for the cardiologist practicing PCI. Success rates of PCI in CTOs have steadily increased over the last 15 yrs because of greater operator experiences, improvements in equipments and procedural techniques. ${ }^{10-11}$ Length of occlusion, duration of occlusion, presence of tapered entry configuration, bridging collaterals and calcification are also important predictors of procedural success. ${ }^{12-13}$ New concept for CTO recanalization using controlled Antegrade and Retrograde Subintimal Tracking (CART) is a favorable strategy for invasive cardiologist. This has shown a feasible, safe and higher success rate, ${ }^{14}$ although, procedural success of PCI of patients with CTO lesion was 55-90\%. ${ }^{15-}$ 16 Most interventional cardiologist has their own set standard within the already framed guidelines by ACC/AHA/ESC. Stone et al ${ }^{14}$ has recommended that in general, when CTO represented by significant lesion in the coronary tree, PCI is warranted in 3 condition: 1) occluded vessel is responsible for the clinical symptoms, 2) Myocardial territory supplied by the occluded vessel, and 3) the likelihood of success is moderate to high $(>60 \%)$ with anticipated major complications like death to be $<1 \%$ and myocardial infarction to be $<5 \%$.

Attempts at CTO revascularization represents of $8-15 \%$ of all PCI. ${ }^{17-19}$ It improves anginal symptoms, exercise tolerance and LV function ${ }^{20}$ In addition, it lessens the incidences of MACE including cardiac mortality. ${ }^{9,21-22}$ The most common mode for PCI failure in CTOs, is the inability to successful passage of a guidewire into the true lumen of the distal vessel. ${ }^{23-24}$ Kinoshita et al has demonstrated that failure to cross guidewire(63\%), long intimal dissection with creation of false lumen (24\%), dye extravasations, failure to cross the lesion with balloon or dilate adequately (2\%) and thrombosis(1.2\%) are the common problems encountered in CTO intervention.
In our present study, we had limitations of singlecentered trial. As most of our patients are not being covered by insurance and noncompliance with follow-up in OPD is difficult. Therefore, we had to limit our study of PCI on these patients up to 30 days after the procedures.

In our present study we found that female are more obese and developed CAD in more advance age than male patients. Admission BP was higher in female either due to obesity or from noncompliance to their current medication. We also found that average number of CAD risk factors were higher in male than female, although male are having one more exclusive $\mathrm{CAD}$ risk factors as being smoker. Among the CAD risk factors dyslipidemia contributed an important role in the development of atherosclerotic CAD followed by HTN, DM and positive FH and smoking (male patient). Incidences of CTO lesion were higher in LAD followed by RCA and LCX of the studied population was consistent with the results of Holmes et al. ${ }^{25}$ Our results are consistent with others studies which showed, that the above mentioned risk factors are the major contributing factor in the development of CAD, specially CTO lesion. Interestingly, we found that that the CTO lesions were more common in patients with unstable angina followed by Ant MI, Inferior MI and NSTEMI.

Patients were followed-up at Cardiac outpatient department. None of them has any complaint of new onset of anginal chest pain, any new changes in repeat ECG and echocardiography. In the present study, none of the patient needed repeat procedures or had MACE like MI, Death, acute Stent thrombosis during in-hospital and 30 days after the procedure.

In the future, we would like to focus on long term survival outcome studies of these patients for up to 6-12 months, if possible angiographically. Effective reduction of in-stent restenosis by Sirolimus-eluting or Paclitaxel-eluting stents versus bare metal stent need to be clarified.

In our present study, none of the patient had procedural complications. We therefore, within limited resources (unavailability of special CTO wires and IVUS), were able to demonstrate that PCI in the CTOs increases procedural success and 30day survival in our population. 


\section{Conclusion:}

CTO lesion is one of most the complex and critical type of CAD lesion. This usually carries a lot of procedural risk during or after successful intervention. For this reason, they, need to be followed up at regular interval to evaluate and see its success as complications are more common. Our future focus, is to study the long-term survival outcome and restenosis rate of CTO lesion either by BMS or DES in the context of Bangladesh. This needs to be clarified more by retrospective as well as by comparative study in a larger population.

\section{References:}

1. Suttorp MJ, Laarman GJ, Rahel BM. Primary stenting of totally occluded native coronary arteries II(PRISON II) study: A randomized comparison of bare metal stent implantation with Sirolimus-eluting stent implantation for the treatment of total coronary occlusion. Circulation 2006;114:921-928.

2. Lei Ge, Lakovou L, Cosgrave J et al. Immediate and mid-term outcomes of Sirolimus-eluting stent implantation for chronic total occlusions. Eur Heart J. 2005;26:1056-1062.

3. Serruys PW, de Jaegere P, Kiemenweji F et al. A comparison of balloon expandable stent implantation with balloon angioplasty in patients with coronary artery disease. N Eng J Med 1994;331:489-495.

4. Fischman DL, Leon MB, Baim DS et al. A randomized comparison of coronary stent placement and balloon angioplasty in the treatment of coronary artery disease. N Engl J Med. 1994;331:496-501.

5. Moses JW, Leon MB, Pompa JJ et al. Sirolimus-eluting stents versus standard stents in patients with stenosis in native coronary artery. $N$ Eng $J$ Med. 2003;349:13151323.

6. Stone GW, Ellis SG, Cox DA. Polymer based Paclitaxeleluting in patients with native coronary artery disease. $N$ Eng J Med 2004;350:221-231.

7. Buller CE, Dzavik V, Carere RG et al: Primary stenting versus balloon angioplasty in occluded coronary arteries: the total occlusion study of Canada (TOSCA). Circulation;100:236-242.

8. Werner GS, Krack A, Scharz G et al. Prevention of lesion recurrence in chronic total occlusion by Paclitaxeleluting stent. J Am Coll Cardiol 2004, 44:2301-6.

9. Stone GW, Kandzari DE, Mehran R et al. Percutaneous recanalization of chronically occluded artery: a consensus document: Part I. Circulation 2005;112:23642372 .

10. Suero JA, Marso SP, Jones PG et al. Procedural outcomes and longterm survival among patients undergoing Percutaneous coronary intervention of a chronic total occlusion in native coronary arteries: a 20 yr experience. J Am Coll of Cardiol 2001.;38:409-414.

11. Ramanathan K, Gao M, Nogareda GJ et al. Successful Percutaneous recanalization of a non-acute occluded coronary artery predicts clinical outcomes and survival. Circulation 2001;1041:II-415 Abstract.
12. Maiello L, Colombo A, Gianrossi R et al. Coronary Angioplasty of chronic occlusions: Factors predictive of procedural success. Am Heart J 1992; 124:581-584.

13. Noguchi T, Miyazaki S, Morii I et al. Percutaneous transluminal coronary angioplasty of chronic total occlusions. Determinants of primary success and longterm clinical outcomes. Catheter Cardiovasc Interv 2000;49:258-264.

14. Surmely JF, Tsuchikane E, Katoh O et al. New concept for CTO recanalization using controlled Antegrade and Retrograde Subintimal Tracking (CART) technique. $J$ Invasive Cardiol 2006;18:334-338.

15. Stone GW, Refart NJ, Moussa I et al. Percutaneous recanalization of chronically occluded coronary arteries: a consensus document: part II. Circulation 2005; 112: 2530-2537.

16. Srivatsa SS, Edwards WD, Boos CM. Histologic correlates of angiographics chronic total coronary artery occlusions influence of occlusion during neovascular channel patterns and intimal plaque composition. $J$ Am coll Cardiol. 1997;29:955-963.

17. Kandzari DE. The challenges of chronic total coronary occlusions: an old problem in a new perspective. J Interv Cardiol 2004;17:259-267.

18. Willams DO, Holubkov R, Yeh W et al. Percutaneous coronary intervention in the current era compared with 1985-1986: the National Heart, Lung and Blood institutes registry's. Circulation 2000;102:2945-2951.

19. Anderson HV, Shaw RE, Brindis RG et al. A contemporary overview of Percutaneous coronary interventions: the American College of CardiologyNational Cardiovascular Data Registry (ACC-NCDR). J Am Coll Cardiol 2002;39:1096-1103.

20. Sirnes PA, Myreng Y, Molstad P. et al. Improvement in left ventricular ejection fraction and wall motion after successful recanalization of chronic coronary occlusions. Eur Heart J 1998;19:273-281.

21. Aziz S, Percutaneous coronary intervention for chronic total occlusions: Improved survival for patients with a successful revascularization procedure compared to a failed perocedure. Transcatheter Cardiovascular Therapeutics(TCT), Washington DC. October 2005.

22. Olivari Z, Rubartelli P, Piscione $\mathrm{F}$ et al. Immediate results and one year clinical outcomes after percutaneous coronary intervention in chronic total occlusions: data from a multicenter prospective observational study (TOASTGISE). J Am Coll Cardiol 2003;41:1672-1678.

23. Safian RD, McCabe CH, Sipperly ME. Initial success and long-term follow-up of Percutaneous transluminal coronary angioplasty in chronic total occlusions versus conventional stenosis. Am J Cardiol 1988;61:23G-28G.

24. Kinoshita et al, Katoh O, Nariyama J. Coronary angioplasty of chronic total occlusions with bridging collaterals vessel: immediate and follow-up outcome from a large single-center experience. $J$ Am Coll Cardiol 1995;26:409-415.

25. Holmes DR Jr, Vlietstra RE, Reeder GS. Angioplasty in Total coronary artery stenosis. J Am Coll Cardiol 1984;3:3:845-9. 